\section{First UK trial of AIDS} vaccine approved

\section{- First step is cautious but safe Twenty volunteers to test prototype}

\section{London}

THE first British trial of a prototype AIDS vaccine was given the go-ahead by the UK's Medical Research Council (MRC) last week.

The phase I trial, which will be carried out under the aegis of the MRC's AIDSrelated research programme, is to begin in September at London's Hammersmith Hospital, where a candidate vaccine known as p24-VLP will be administered to 20 healthy seronegative volunteers. Their immune response to the vaccine will be monitored for up to a year before a decision about further trials is made.

Developed by Oxford-based British Biotechnology Limited, p24-VLP consists of a fragment of an HIV protein known as p24 presented on the surface of a newlyemergent vaccine carrier known as a virus-like particle (VLP). Although not infectious, VLPs possess some of the basic elements of retroviruses, and can be prepared easily in a pure state from genetically engineered yeast cells. Researchers at BBL have shown that VLPs are able to carry proteins that induce $\mathrm{HIV}$-specific immune responses in animals.

News of the trials comes almost three years after the start of the first clinical trial of a prototype AIDS vaccine in the United States. Jane Cope, who is orchestrating the MRC's AIDS vaccine strategy, says that the MRC "didn't want to rush into human studies" without first laying the foundations of a well organized trial system.

But aside from caution, there may be other reasons why the announcement of the first UK trial has been slow in coming. One factor, according to Alan Kingsman, director of research at British Biotechnology Limited, is the dearth of small biotechnology companies in Britain: "The big companies haven't been keen to take it [vaccine development] on", he says. Jonathon Weber of the Hammersmith Hospital, who will be in charge of the clinical trials, notes that most US trials have focused simply on the response of the human immune system to large quantities of crude HIV proteins or peptides. The British trial, however, has a different emphasis: to test the feasibility of using VLPs as novel carriers for 'immunogenic' HIV peptides in humans.

Caution is also evident in the choice of p24 as the vaccine's immunogenic component. Most vaccines tested so far have used the HIV envelope proteins gp160 and gp120, on the grounds that these proteins are exposed on the surface of the virus and so should be strongly immunogenic. In the past, however, questions have been raised about the safety of envelope-derived vaccines, which some researchers have suggested could act to suppress the immune system. No such concern has been expressed over p24, largely because, being a core protein of $\mathrm{HIV}$, it does not participate directly in the virus's interaction with T cells.

Kingsman and Weber agree that p24 alone is unlikely to provide protective immunity against HIV. They view the trial as the first step towards developing a vaccine in which VLPs carry a 'cocktail' of HIV immunogenic protein fragments. The p24 protein is known to stimulate helper $T$ cells in animals and so might play a part in creating protective immunity.

Although trial voluteers will produce antibodies to HIV, the MRC has given assurances that no one will be mistakenly thought to have HIV infection, and so volunteers should have no difficulty obtaining life assurance or mortgages on medical grounds.

The researchers were coy about how they intend to recruit volunteers, but it is unlikely that they will need to call on members of the public.

\section{Second round}

\section{Washington}

FIFTEEN months after the appearance of their first paper announcing the discovery of "cold fusion", Martin Fleischmann and Stanley Pons have published a second paper, 56 pages long, in which they give a full account of the electrochemistry and calorimetry behind their claim that electrolysis of heavy water with palladium cathodes generates more heat than conventional chemistry and physics can explain. The paper, written by Fleischmann, Pons, M.W. Anderson, L.J. Li and M. Hawkins, all of the Department of Chemistry at the University of Utah, appeared in the 25 July 1990 issue of the Journal of Electroanalytic Chemistry and Interfacial Electrochemistry, the same journal in which a short paper by Fleischmann, Pons and Hawkins appeared on 10 April 1989.

According to an announcement by Elsevier Sequoia, the journal's publisher, the new paper addresses only questions of tion on the emission of nuclear particles or radiations which would be expected if "cold fusion" reactions are indeed occurring. The accuracy of the calorimetric results is demonstrated, Elsevier says, by comparisons of palladium-heavy water cells with control experiments using palladium electrodes in light water and platinum electrodes in heavy water. In the absence of direct evidence for nuclear processes in the cells, the implication that fusion is responsible for the excess heat is drawn "by elimination". electrochemistry, and contains no informa-
David Lindley

\section{IMAGE UNAVAILABLE FOR COPYRIGHT REASONS}

Light speed - a solar-powered car leaves engine troubles behind on its way to fourth place in the General Motors Sunrayce earlier this month. The 1,641-mile race for vehicles powered by sunlight was won by an entry from the University of Michigan. (AP) 